\title{
A cross sectional study of the reasons for deferral of voluntary blood donors at a district blood bank attached to a medical college hospital in southern Karnataka
}

\author{
K L Shoba ${ }^{1}$, P Subhas Babu ${ }^{2, *}$ \\ ${ }^{1}$ Assistant Professor, ${ }^{2}$ Associate Professor, ${ }^{1}$ Dept. of Pathology, ${ }^{2}$ Dept. of Community Medicine, Mandya Institute of Medical \\ Sciences, Karnataka \\ *Corresponding Author: \\ Email: p.subhash.babu@gmail.com
}

Received: $04^{\text {th }}$ October, 2017

Accepted: $25^{\text {th }}$ November, 2017

\begin{abstract}
Introduction: The study objectives were to determine the demographic profile of voluntary donors who were deferred from donating blood and the different reasons for deferral of those donors who intended to donate blood to the hospital blood bank.

Materials and Methods: A cross sectional, record based study was done from March 2014 to February 2015 at the blood bank. The data was entered into Microsoft ${ }^{\circledR}$ Excel $^{\mathrm{TM}}$ Spreadsheet and was analysed using the same. Descriptive statistics were obtained.

Result: A total of 7,319 potential donors were screened by the blood bank of whom, 7000 (95.64\%) were selected for donating blood and 319 (4.36\%) were found ineligible for blood donation for various reasons. Of all the potential blood donors, male donors were 6991, of whom $6783(97.02 \%)$ were selected and $208(2.98 \%)$ were deferred from donating blood. While out of 328 registered female donors, $217(66.15 \%)$ were selected and 111(33.84\%) were deferred. Permanent deferral rates were comparatively higher for males than females and temporary deferrals, were higher among female donors. A major proportion of the deferred donors were between the age group of 18-30 years. Anemia, medication intake, being underweight and underage were predominant reasons for deferral among temporary deferrals.

Conclusion: A significant number of potential blood donors are deferred for various preventable and treatable reasons. The deferred donors need to be actively pursued, so that they can contribute by donating blood and saving lives as they may get demotivated, when they are deferred from donating blood.
\end{abstract}

Keywords: Voluntary blood donors, Deferral.

\section{Introduction}

Voluntary blood donation forms the basis for procurement of safe blood for patient care across the world and India.

One of the key strategies of blood transfusion services under the National AIDS control programme in India to meet the safe blood requirements of the country is to encourage and promote regular voluntary blood donation without any monetary benefits to the donors. The Supreme Court of India in its judgment of 1996 on blood safety, heralded the creation of National Blood Transfusion Council and removal of professional blood donation. ${ }^{1}$

Under the voluntary blood donation programme, a standard universal guideline for donor selection is followed for screening voluntary blood donors to ensure procurement of safe blood and eliminate the transmission of blood borne infections and immunological reactions. ${ }^{2}$

WHO envisions the achievement of $100 \%$ voluntary non-remunerated blood donation in every country of the world as voluntary non-remunerated blood donors are the foundation of a safe, sustainable blood supply. Without a system, based on voluntary unpaid blood donation, particularly regular voluntary donation, no country can provide sufficient blood for all patients who require transfusion. ${ }^{3}$

\section{Objectives of the study}

a. To determine the demographic profile of donors who were deferred from donating blood

b. To determine the different reasons for deferral of donors who intended to donate blood to the hospital blood bank

\section{Materials and Methods}

Type of Study: Cross sectional, record based, descriptive study

Study Duration: One year (from March 2014 to February 2015)

Study Setting: Hospital blood bank and the camps conducted by the blood bank for voluntary blood donation drive

Sample Size: 319 (all donors who were deferred during the study period)

The records of all prospective blood donors who presented to the blood bank as well as at voluntary blood donation camps from March 2014 to Feb 2015 were reviewed. The blood donors were eligible to donate blood if they met the criteria as mandated under the NACO guidelines (Directorate General of Health Services guideline, 2003, Ministry of Health and Family Welfare). ${ }^{4}$ The donors were interviewed using a pre-tested semi structure questionnaire and examination 
for fitness to donate blood. The examination included weight, vital parameters like pulse, blood pressure, and temperature. Haemoglobin estimation of the donors was also done.

As per the guidelines potential donors are to be between 18years and 60 years of age, weight should not be less than $45 \mathrm{~kg}$, pulse rate $60-100 \mathrm{~b} / \mathrm{m}$, temperature 37.2 - $37.7^{\circ} \mathrm{C}$, systolic blood pressure between 100 $180 \mathrm{~mm}$ of $\mathrm{Hg}$, diastolic blood pressure $50-100 \mathrm{~mm}$ of $\mathrm{Hg}$ and haemoglobin level of $12.5 \mathrm{~g} / \mathrm{dl}$ or more were accepted for blood donation.

All blood donations done during the study period were considered as independent attempts even if done by the same donor on different occasions during the study period for the sake of simplifying analysis.

The data was entered into Microsoft Excel spreadsheet and were analysed using Microsoft excel.
The data was segregated with respect to age, sex and reasons for deferral (temporary and permanent)

Ethical Consideration: Approval was obtained from the institutional ethics committee before the commencement of this study.

\section{Results}

During the one year study period, from March 2014 to Feb 2015, a total of 7,319 potential donors were screened at our blood bank including outdoor voluntary blood donation camps. Of the total 7319 donors 7000 $(95.64 \%)$ were selected for blood donation and 319 $(4.36 \%)$ were deferred from blood donation, for various reasons.

Table 1: Showing distribution of registered, selected and deferred donors based on their gender

\begin{tabular}{|l|c|c|c|}
\hline Donors & Male & Female & Total \\
\hline Registered & 6991 & 328 & $7319(\mathrm{n})$ \\
\hline Selected & $6783(97.02 \%)$ & $217(66.15 \%)$ & $7000(95.64 \%)$ \\
\hline Deffered & $208(2.98 \%)$ & $111(33.84 \%)$ & $319(4.35 \%)$ \\
\hline
\end{tabular}

As depicted in the above table, of the 6991 registered male donors, $6783(97.02 \%)$ were selected and $208(2.98 \%)$ were deferred from donating blood. While out of 328 registered female donors, 217
$(66.15 \%)$ were selected and $111(33.84 \%)$ were deferred. The overall deferral rates were relatively higher for females compared to males.

Table 2: Showing distribution of deferred donors on the basis of temporary or permanent deferral

\begin{tabular}{|l|c|c|c|}
\hline Deferrals & Male & Female & Total \\
\hline Temporary & $162(77.81 \%)$ & $109(98.19 \%)$ & $271(84.95 \%)$ \\
\hline Permanent & $46(22.11 \%)$ & $02(1.80 \%)$ & $48(15.04 \%)$ \\
\hline & 208 & 111 & 319 \\
\hline
\end{tabular}

temporary deferrals which were higher among female

Permanent deferral rates were comparatively donors. higher for males than females when compared to

Table 3: Showing the different reasons for temporary deferral among the screened donors

\begin{tabular}{|l|c|c|c|c|}
\hline Reason for deferral & Male & Female & Total & $\begin{array}{c}\text { \% of temporary } \\
\text { deferrals }\end{array}$ \\
\hline Low Hb & 16 & 15 & 66 & 24.35 \\
\hline Medication & 34 & 01 & 35 & 12.91 \\
\hline Under age & 25 & 08 & 33 & 12.17 \\
\hline Under weight & 15 & 14 & 29 & 10.70 \\
\hline Low BP & 13 & 09 & 22 & 8.11 \\
\hline Alcohol intake & 18 & 00 & 18 & 6.64 \\
\hline Menstruation & $\mathrm{NA}$ & 17 & 17 & 6.27 \\
\hline Tattoo & 14 & 01 & 15 & 5.53 \\
\hline Jaundice & 06 & 01 & 07 & 2.58 \\
\hline Infection & 05 & 01 & 06 & 2.21 \\
\hline Fever & 04 & 01 & 05 & 1.84 \\
\hline Recent surgery & 04 & 01 & 05 & 1.84 \\
\hline Ear piercing & 00 & 03 & 03 & 1.10 \\
\hline Tooth extraction & 02 & 01 & 03 & 1.10 \\
\hline Allergy & 02 & 00 & 02 & 0.73 \\
\hline Fasting/food not taken & 01 & 01 & 02 & 0.73 \\
\hline
\end{tabular}




\begin{tabular}{|l|c|c|c|c|}
\hline in last 4 hours & & & & \\
\hline Diarrhea & 01 & 00 & 01 & 0.36 \\
\hline Rabies vaccine & 01 & 00 & 01 & 0.36 \\
\hline Recent donor & 01 & 00 & 01 & 0.36 \\
\hline Total & 162 & 109 & 271 & $100 \%$ \\
\hline
\end{tabular}

Anemia, Medication intake, being underweight and underage were predominant reasons for deferral among temporary deferrals.

Table 4: Showing the reasons for permanent deferrals among screened donors and their relative proportion

\begin{tabular}{|l|c|c|c|c|}
\hline Reason for deferral & Male & Female & Total & $\begin{array}{c}\text { \% of permanent } \\
\text { deferrals }\end{array}$ \\
\hline High BP & 39 & 00 & 39 & 81.25 \\
\hline Diabetes & 02 & 01 & 03 & 6.25 \\
\hline Epilepsy & 02 & 00 & 02 & 4.16 \\
\hline Over age & 02 & 00 & 02 & 4.16 \\
\hline Heart disease & 00 & 01 & 01 & 2.08 \\
\hline Kidney disease & 01 & 00 & 01 & 2.08 \\
\hline Total & 46 & 2 & 48 & $100 \%$ \\
\hline
\end{tabular}

High blood pressure was the predominant reason for permanent deferrals $(81.25 \%)$ while rest of the proportion was due to chronic diseases and overage.

Table 5: Showing the top five reasons for deferrals in the screened male and female blood donors

\begin{tabular}{|l|c|c|l|c|c|}
\hline \multicolumn{3}{|c|}{ Male (208) } & \multicolumn{3}{c|}{ Female (111) } \\
\hline Causes & Number & $\begin{array}{c}\text { \% of } \\
\text { deferrals }\end{array}$ & Causes & Number & $\begin{array}{c}\text { \% of } \\
\text { deferrals }\end{array}$ \\
\hline High BP & 39 & 18.75 & Low Hb & 50 & 45.04 \\
\hline Medication & 34 & 16.34 & Menstruation & 17 & 15.31 \\
\hline Under age & 25 & 12.01 & Under weight & 14 & 12.61 \\
\hline Alcohol & 18 & 8.65 & Low BP & 09 & 8.10 \\
\hline Low Hb & 16 & 7.69 & Under age & 08 & 7.20 \\
\hline
\end{tabular}

Table 6: Showing the age wise distribution of deferred blood donors

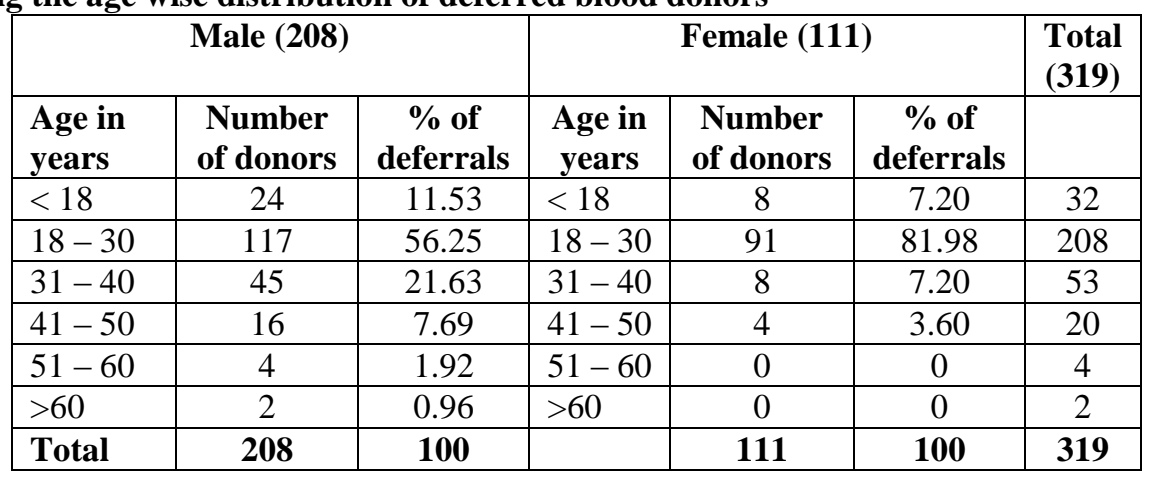

A major proportion of the deferred donors (56.25\%) were aged between 18 years and 30 years of age.

\section{Discussion}

In this study of the 7319 registered blood donors, 319 persons were deferred from donating blood for various reasons. The proportion of deferrals was $4.35 \%$. Different researchers have reported a varied proportion

of donor deferrals. Some studies have reported low rates between 4\%-6\% (Talonu. T, Sundar et.al) ${ }^{5,6}$ 
A donor deferral rate of $4.35 \%$ obtained in this study is similar to deferral rate obtained in the study done by Talonu. $\mathrm{T}$, et al in papua New Guinea (deferral rate $4 \%) .^{5}$

Adherence to the screening criteria for blood donors, will help keep the proportion of deferrals to an acceptable minimum.

The ultimate aim of any safe blood transfusion service is to ensure the safety and health of the recipient and the donor while obtaining and transfusing blood and blood products. This mandates a strict adherence to protocol while selecting potential blood donors. In ensuring this some potential voluntary donors may be turned away which may demotivate them and may not return for blood donation again.

Causes of deferral were many and were broadly classified temporary and permanent. More number of deferrals were temporary constituting about $84.95 \%$ and permanent deferrals, about $15.04 \%$. This was similar to a study conducted by Sundar et.al ${ }^{6}$ (temporary $84 \%$ permanent $16 \%$ ). Custer et.al reported $68.5 \%$ temporary and $31.5 \%$ permanent deferral. ${ }^{11}$

The common causes for temporary deferral in females were low haemoglobin level, menstruation and being underweight. In males donors who were deferred medication, underage and alcohol intake. In a study by Halperin et al ${ }^{12}$ the 3 most common temporary deferral are low haemoglobin level, colds/sour throat and fever were as that by Ranveet et.al ${ }^{13}$ underweight, under age, and low haemoglobin levels.

When voluntary blood donors are deferred for a reason which is temporary, they need to be informed of the reason and the duration for deferral, as it has been found to have a negative impact on their probability of return for future blood donation. Zou et.al ${ }^{14}$ have reported potential donor loss after a deferral. Therefore all deferred individuals must be informed about the cause and period deferral and prompt counselling to help them overcome the problem. This will also help blood bank to retain future donor pool.

The commonest cause for permanent deferral in our study was high blood pressure $(81.25 \%)$. This was similar to studies conducted by Sunder et.al and Bahadur et.al. ${ }^{15}$ The probable reason could be sight of blood, first time blood donation, fear of phlebotomy and white coat hypertension, stress, exercise. Hypertension often goes undetected and could be an incidental finding while screening donors.

A low haemoglobin level in the blood is the most common cause of temporary deferral among the blood donors in this study (24.35\%). This finding is consistent with many other studies both in the developed and developing countries. In India, the required haemoglobin cut off level is $12.5 \mathrm{gm} / \mathrm{dl}$ both for male and female donors for blood donation. In Canada $2 \%$ of the blood donors do not meet the minimum acceptable haemoglobin level,(Ali AM) ${ }^{16}$ the figure is higher in developing countries as pointed in a study conducted by Hinal Gajjar et.al (59.55\%). ${ }^{17}$

Similar to the findings in a study done by Hinal Gajjar et.al. ${ }^{17}$ a large proportion of the deferred donors were aged between 18 years and 30 years $(65.20 \%)$ which also incidentally is the major age group to which most of the voluntary donors belong to. This points in the direction of the nutritional status of the youth, especially micro nutrient levels that need to be improved which will significantly reduce deferrals due to temporary reasons especially anemia.

\section{References}

1. Blood Transfusion Services, National AIDS Control Organization [Internet]. [last accessed on 16.09.2017].Available from : http://naco.gov.in/bloodtransfusion-services.

2. Voluntary Blood Donation Programme-An operational Guideline. National AIDS Control Organization, Ministry of Health and Family Welfare.[Internet]; 2007 [last accessed on 16.09.2017] Available from: http://naco.gov.in/sites/default/files/voluntary\%20blood\% 20donation.pdf

3. Towards $100 \%$ voluntary blood donation; A global framework for action. World Health Organization [Internet] [last accessed on 16.09.2017] Available from: http://www.who.int/bloodsafety/publications/9789241599 696/en/.

4. Saran, R.L, Editor. Organization of Blood transfusion services in transfusion medicine. Technical manual, Second edition; WHO DGHS guidelines, Ministry of Health and Family Welfare: 1-6 (Directorate General of Health Services guideline, 2003, Ministry of Health and Family Welfare) 2003.

5. Talonu T. Causes of volunteer blood donor rejection in Papua New Guinea. P N G Med J. 1983;26:195-7.

6. Sunder P, Sangeetha SK, Seema DM, Marimuthu P, Shivanna N. Pre-donation deferral of blood donors in South Indian Set-up: An Analysis. Asian J Transfus Sci 2010 July;4(2):113-5.

7. Tomasulo PA, Anderson AJ, Paluso MB, Gutschenritter MA, Aster RH. A study of criteria for blood donor deferral. Transfusion.2003;20(5):511-18.

8. Charles KS, Hughes P, Gadd R, Bodkyn CJ, Rodriquez $M$. Evaluation of blood donor deferral causes in the Trinidad and Tobago National Blood Transfusion Service. Transfusion Med. 2010;20(1):11-14.

9. Di Lorenzo Oliveria C, Loureiro F, de Bastos MR, Proietti FA, Carneiro-Proietti AB. Blod donor deferral in Minas Gerais State, Brazil: blood centers as sentinels of urban population health. Transfusion. 2009;49(5):851-7.

10. Madan N, Qadiri J, Akhtar F.Study of Blood Donor Profile at a Tertiary Care Teaching Hospital. Journal of the Academy of Hospital Administration. 2005;17(2):3-4.

11. Custer B, Johnson ES, Sullivan SD, Hazlet TK, Ramsey SD, Hirschler NV, et al. Quantifying losses to the donated blood supply due to donor deferral and miscollection. Transfusion. 2004;44:1417-26.

12. Halperin D, Baetens J, Newman B. The effect of shortterm, temporary deferral on future blood donations. Transfusion. 1998;38:181-3.

13. Ranveet K, Sabita B, Neelam M. A Reappraisal of underlying causes in donor deferral. Ann Natl Acad Med Sci. 2002;38:93-9. 
14. Zou S, Musavi F, Notari EP, Rios JA, Trouern-Trend J, Fang CT. Donor deferral and resulting donor loss at the American Red Cross Blood Services, 2001 through 2006.Transfusion. 2008;48(12):2484-6.

15. Bahadur S, Jain S, Goel RK, Pahuja S, Jain M. Analysis of blood donor deferral characteristics in Delhi, India. Southeast Asian J Trop Med Public Health. 2009;40(5):1087-91.

16. Ali AM, Goldsmith $\mathrm{CH}, \mathrm{McAvoy}$ AT, Ali MA, Blajchman MA. A prospective study evaluating the lowering of hemoglobin standards for blood donors. Transfusion. 1989;29:268-72.

17. Hinal Gajjar, F R Shah, N R Shah, C K Shah. Whole blood donor deferral analysis at General hospital blood bank- A retrospective study. NHL Journal of Medical Sciences. July 2014;3(2):72-76. 